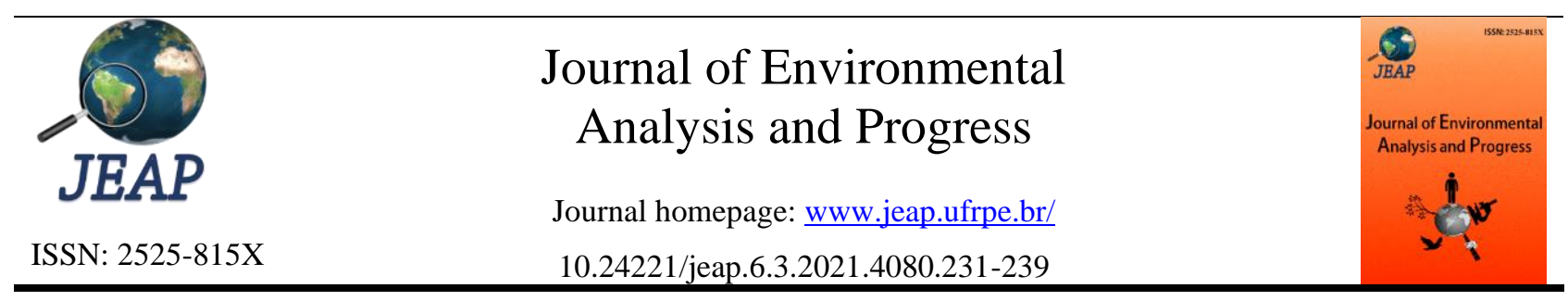

\title{
Influência do ferro e do sulfato na rota metanogênica de degradação anaeróbica do paracetamol
}

\section{Iron and Sulfate influence in methanogenesis route in anaerobic digestion of acetaminophen}

\author{
Emanuele Diógenes Guerra ${ }^{a}$, Deivid Sousa de Figueiroa ${ }^{a}$, Luiza Feitosa Cordeiro de Souza ${ }^{a^{*}}$ \\ ${ }^{a}$ Centro Universitário Tabosa de Almeida- ASCES-UNITA. Av. Portugal, 584, Universitário, Caruaru-PE, Brasil. CEP: \\ 55016-400. E-mail: manu_diogenes@hotmail.com, deividfigueiroa@asces.edu.br, luizas@gmail.com (*Autor \\ correspondente).
}

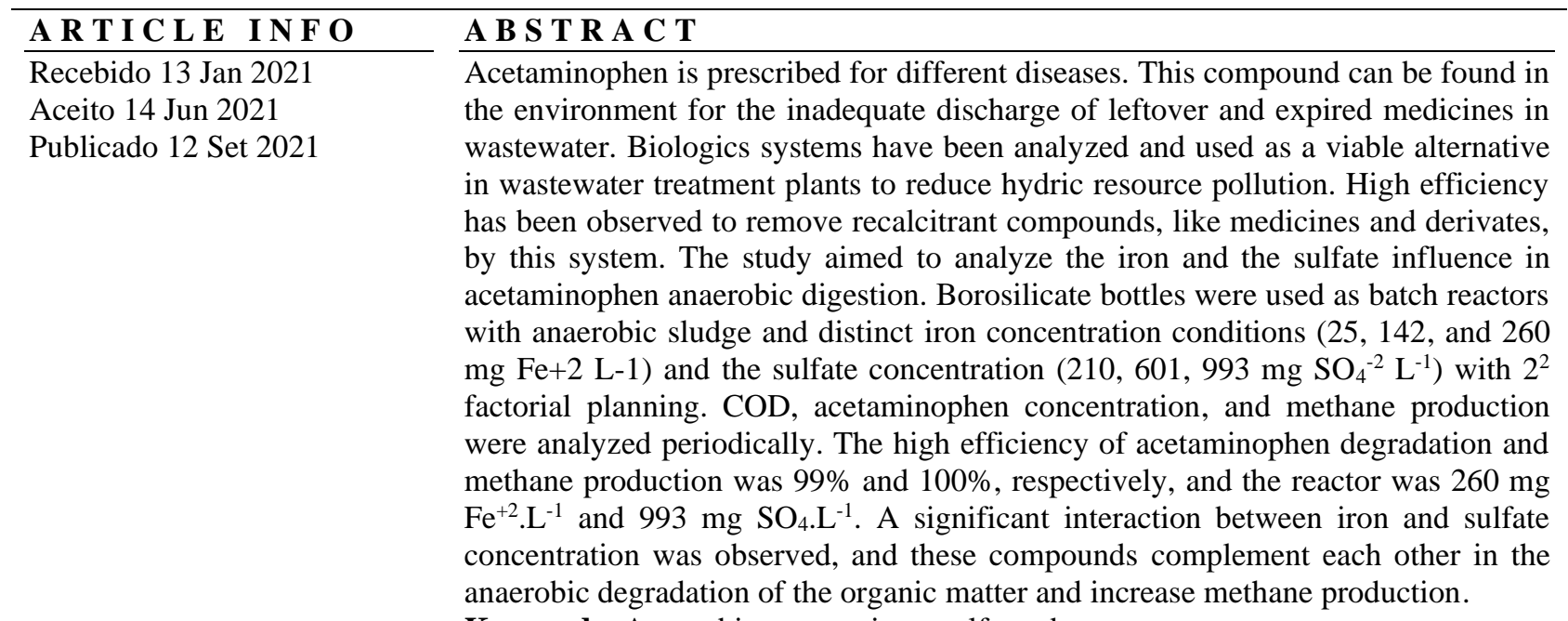

Keywords: Anaerobic reactor, iron, sulfate, drug.

\section{R E S U M O}

O paracetamol (acetaminofeno) é um fármaco utilizado no tratamento de várias doenças. Este composto pode ser encontrado no meio ambiente devido ao descarte de medicamentos viáveis ou vencidos no esgoto doméstico. Para não contaminar os corpos hídricos, sistemas biológicos têm sido analisados e utilizados como sistemas de tratamento de esgoto contendo diferentes tipos de compostos químicos, incluindo os provenientes de medicamentos. O estudo analisou a influência do ferro e do sulfato na digestão anaeróbia do paracetamol. Foram utilizadas garrafas-reator, com lodo anaeróbio, em regime de batelada, com condições distintas de concentração de ferro $\left(25,142\right.$ e $\left.260 \mathrm{mg} \mathrm{Fe}^{2+} \mathrm{L}^{-1}\right)$ e sulfato $\left(210,601,993 \mathrm{mg} \mathrm{SO}_{4}^{-2} \mathrm{~L}^{-1}\right)$, seguindo um planejamento fatorial $2^{2}$. Foram analisados, periodicamente, a DQO, concentração do paracetamol e produção de metano. A máxima eficiência de degradação do paracetamol e de produção de metano, $99 \%$ e $100 \%$, respectivamente, ocorreu no reator com $260 \mathrm{mg} \mathrm{Fe}^{2+} \mathrm{L}^{-1}$ e $993 \mathrm{mg} \mathrm{SO}_{4}^{-2} \mathrm{~L}^{-1}$. Observou-se que existe uma interação entre o ferro e o sulfato e que eles se complementam na degradação da matéria orgânica nos reatores anaeróbios.

Palavras-Chave: Reatores anaeróbios, ferro, sulfato, fármaco.

\section{Introdução}

$\mathrm{O}$ analgésico comumente prescrito pelos profissionais da área de saúde no Brasil é o paracetamol (Brasil, 2016; Borges et al., 2018). Por ser da classe do MIPs (Medicamentos Isentos de Prescrição ou de venda livre), este analgésico é consumido pela população indiscriminadamente de forma preventiva, curativa, com e sem prescrição 
de um profissional e até sem a confirmação do quadro clínico (Bachur et al., 2017). Este fármaco também é amplamente utilizado no tratamento de diversas outras enfermidades como enxaquecas dores associadas a resfriados comuns, dor de cabeça, dor no corpo, dor de dente, dor nas costas, dores musculares, dores leves associadas a artrites e dismenorreia, febre amarela, dengue, Chikungunya e Zika (Brasil, 2013).

O paracetamol ou acetaminofeno é o metabólito ativo da fenacetina e um analgésico derivado do alcatrão. É um composto orgânico constituído por carbono, nitrogênio e oxigênio. Ele é descrito, frequentemente, como um dos fármacos mais consumidos no planeta e, quando administrado em doses terapêuticas, cerca de 90 a $100 \%$ pode ser excretado pela urina, sem alteração no primeiro dia de ingestão (Goodman \& Gilman, 2003). Portanto, este composto pode ser carreado pelo esgoto para as estações de tratamento de efluentes (ETEs) ou direto para os corpos hídricos, sem nenhuma alteração.

No Brasil, a população costuma descartar os medicamentos que sobraram do tratamento juntamente com lixo doméstico ou com o esgoto sanitário. No município de Caruaru-PE, aproximadamente $88 \%$ da população entrevistada pelo projeto "Descarte de Medicamentos no Meio Ambiente" destinava as sobras de seus medicamentos, ou os medicamentos vencidos, no lixo doméstico (Guerra et al., 2017). Segundo a legislação vigente a respeito da Política Nacional dos Resíduos Sólidos (Lei n ${ }^{\circ} 12.305 / 10$ ), a correta disposição desse tipo de resíduo deveria ser efetuada em locais adequados para resíduos especiais (Brasil, 2010). Entretanto, apenas 59\% do resíduo sólido total coletado no Brasil é destinado, adequadamente, em aterros sanitários (ABRELPE, 2017).

Fármacos de diversas classes terapêuticas, como antibióticos, hormônios, anti-inflamatórios entre inúmeros outros têm sido detectados em esgotos doméstico, águas superficiais e subterrâneas (Bila \& Dezotti, 2003). O crescimento no consumo de paracetamol está provocando um aumento na concentração desse fármaco em estações de tratamento de esgoto. Na cidade de Campinas, São Paulo, foram detectadas concentrações de paracetamol de $0,018 \mathrm{mg} \mathrm{L}^{-1} \mathrm{e}$ $0,006 \mathrm{mg} \mathrm{L}^{-1}$ em esgotos domésticos brutos e tratados, respectivamente, na ETE Samambaia em 2006, e concentrações inferiores a $0,025 \mathrm{mg} \mathrm{L}^{-1} \mathrm{em}$ águas superficiais (Ghiselli \& Jardim, 2007). Em 2009 foram encontradas concentrações de $1,5 \mathrm{mg}$ $\mathrm{L}^{-1}$ de paracetamol no Córrego da Onça, em Mato Grosso do Sul (Américo, Minillo \& Carvalho, 2012).
Os sistemas biológicos, aeróbios e anaeróbios, são os mais utilizados em estações de tratamento de esgoto. Os sistemas anaeróbios vêm se destacando nos países de clima tropical devido à sua tolerância a elevadas cargas orgânicas e alta eficiência de remoção destes compostos, geração de resíduos naturais, pequena área de ocupação, baixos custos de implantação e operação, baixo consumo de energia e a produção de biogás. Esse sistema permite a operação com elevados tempos de retenção de sólidos e baixos tempos de detenção hidráulica (TDH) (Chernicharo, 2007).

Em sistemas anaeróbios de tratamento, microrganismos distintos convivem de forma harmônica. Isto é, uma espécie degrada parcialmente um composto, gerando um composto menor que é consumido por outro grupo de microrganismos, até a formação de um composto estável como o metano $\left(\mathrm{CH}_{4}\right)$, hidrogênio $\left(\mathrm{H}_{2}\right)$, gás carbônico $\left(\mathrm{CO}_{2}\right)$ ou ainda gás sulfídrico $\left(\mathrm{H}_{2} \mathrm{~S}\right)$ (Chen, Cheng \& Creamer, 2008). Existem diferentes rotas anaeróbias e, em cada uma delas, é formado um tipo diferente de composto estável. A produção de hidrogênio é realizada principalmente por microrganismos metanogênicos hidrogenotróficos, mas também por bactérias redutoras de sulfato (Szarblewski, Schneider \& Machado, 2012). Quando é identificado elevadas concentrações de sulfato em águas residuárias, os compostos intermediários acabam sendo usados pelas bactérias sulforedutoras. Elas passam a competir com as bactérias fermentativas, acetogênicas e metanogênicas (produtoras de metano), pelos substratos disponíveis no reator. Por ser uma via mais favorável termodinamicamente que a metanogênese, a remoção de demanda química de oxigênio (DQO) é estabilizada pela rota da sulfetogênese com a produção final de hidrogênio e gás sulfídrico (Chernicharo, 2007).

A carência de aceptores de elétrons em condição anaeróbia é o principal fator limitante do crescimento de microrganismos. O ferro é um aceptor que em abundância se sobrepõe aos demais aceptores. Muita energia é consumida nas reações de fluxo reverso de elétrons, para que seja obtido o poder redutor necessário à fixação de $\mathrm{CO}_{2}$ (Madigan, 2010; Silva, 2012). O ferro ferroso pode ser oxidado por bactérias fototróficas, nesse caso, o ferro ferroso é utilizado como doador de elétrons que supre as necessidades energéticas e o poder de redução dos microrganismos na redução de $\mathrm{CO}_{2}$ (Madigan, 2010). Desta forma, as bactérias redutoras de ferro formam mais uma possível rota de degradação da matéria orgânica, competindo com as rotas metanogênicas e sulfetogênicas.

São muitos os benefícios dos sistemas anaeróbios para o tratamento de diferentes tipos de 
efluentes, como o baixo custo de operação e manutenção e elevada eficiência. Estudos que ampliem os conhecimentos sobre os efeitos estimulantes e inibidores neste processo devem ser incentivados e, com isso, ampliar sua aplicação e sua eficiência. . O estudo objetivou avaliar a influência do ferro $\mathrm{e}$ do sulfato na rota metanogênica de digestão anaeróbia do fármaco paracetamol em águas residuária.

\section{Material e Métodos \\ Reatores biológicos anaeróbios em escala de batelada}

As garrafas-reator eram de borosilicato com volume total e útil de 610 e $550 \mathrm{~mL}$, respectivamente, correspondendo a um headspace de $10 \%$. Nas tampas de cada garrafa-reator havia septos de borracha nitrilada onde foram inseridas duas agulhas, uma de $0,7 \times 25 \mathrm{~mm}$ para permitir a saída do gás e outra de $25 \mathrm{G}$ x $90 \mathrm{~mm}$ para coletar e analisar amostras.

Utilizou-se um planejamento fatorial $2^{2}$, com um ponto central em triplicata, sendo as concentrações de ferro e a de sulfato os fatores a serem analisados. A escolha dos níveis de cada fator foi baseada na literatura, a qual informou a quantidade mínima para a sobrevivência dos microrganismos e a quantidade necessária para favorecer cada rota (Chernicharo, 2007; Callado, Damianovic \& Foresti, 2017). Os valores mínimos (-1) foram: $25 \mathrm{mg} \mathrm{Fe}^{2+} \mathrm{L}^{-1}$ e $210 \mathrm{mg} \mathrm{SO}_{4}^{-2} \mathrm{~L}^{-1}$, os valores máximos (+1) foram $260 \mathrm{mg} \mathrm{Fe}^{2+} \mathrm{L}^{-1} \mathrm{e} 993$ $\mathrm{mg} \mathrm{SO}_{4}^{-2} \mathrm{~L}^{-1} \mathrm{e}$ os pontos centrais (0) foram $142 \mathrm{mg}$

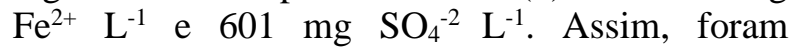
inoculados quatro reatores, em diferentes condições, e três reatores com o valor médio (triplicata do ponto central), resultando em um total de sete reatores.

\section{Composição dos reatores}

Os reatores foram inoculados com lodo granular (2 $\left.\mathrm{g} \mathrm{SSV} \mathrm{L}^{-1}\right)$, substrato (200 mg DQO L$\left.{ }^{1}\right)$, solução de paracetamol $\left(30 \mathrm{mg} \mathrm{L}^{-1}\right)$, solução de macro e micronutrientes $(20 \%$ do volume útil do reator) e solução complementar de ferro $(25,142 \mathrm{e}$ $\left.260 \mathrm{mg} \mathrm{Fe}{ }^{2+} \mathrm{L}^{-1}\right)$ e de sulfato $(210,601,993 \mathrm{mg}$ $\mathrm{SO}_{4}^{-2} \mathrm{~L}^{-1}$ ). O lodo usado foi proveniente de uma ETE industrial de cervejaria, com concentração de $100 \mathrm{~g} \mathrm{SSV} \mathrm{L}^{-1}$. O substrato foi formado por uma composição simulando a água residuária, composta por uma solução de amido (364 $\left.\mathrm{mg} \mathrm{L}^{-1}\right)$, sacarose (112 $\mathrm{mg} \mathrm{L}^{-1}$ ), caldo de carne $\left(332,8 \mathrm{mg} \mathrm{L}^{-1}\right)$, celulose $\left(54,4 \mathrm{mg} \mathrm{L}^{-1}\right)$ e óleo de soja comercial (81,6 $\left.\mathrm{mg} \mathrm{L}^{-1}\right)$, resultando em uma concentração de DQO de $800 \mathrm{mg} \mathrm{O}_{2} \mathrm{~L}^{-1}$ (Torres, 1992).

A solução de nutrientes adicionada era composta por macronutrientes, $\mathrm{NH}_{4} \mathrm{Cl}\left(0,280 \mathrm{~g} \mathrm{~L}^{-}\right.$ $\left.{ }^{1}\right), \mathrm{K}_{2} \mathrm{HPO}_{4}\left(0,252 \mathrm{~g} \mathrm{~L}^{-1}\right), \mathrm{MgSO}_{4} .7 \mathrm{H}_{2} \mathrm{O}(0,100 \mathrm{~g}$ $\left.\mathrm{L}^{-1}\right), \mathrm{CaCl}_{2}\left(0,007 \mathrm{~g} \mathrm{~L}^{-1}\right), \mathrm{NaHCO}_{3}\left(3,316 \mathrm{~g} \mathrm{~L}^{-1}\right)$, extrato de levedura $\left(0,100 \mathrm{~g} \mathrm{~L}^{-1}\right)$ e, solução de micronutrientes, $\mathrm{FeCl}_{2} .4 \mathrm{H}_{2} \mathrm{O}\left(2,000 \mathrm{~g} \mathrm{~L}^{-1}\right), \mathrm{ZnCl}_{2}$ $\left(0,050 \quad \mathrm{~g} \quad \mathrm{~L}^{-1}\right), \quad \mathrm{MnCl}_{2} \cdot 4 \mathrm{H}_{2} \mathrm{O} \quad\left(0,500 \mathrm{~g} \mathrm{~L}^{-1}\right)$, $\mathrm{NiCl}_{2} \cdot 6 \mathrm{H}_{2} \mathrm{O}\left(0,142 \mathrm{~g} \mathrm{~L}^{-1}\right), \mathrm{NaSeO}_{3} .5 \mathrm{H}_{2} \mathrm{O}(0,164 \mathrm{~g}$ $\left.\mathrm{L}^{-1}\right), \mathrm{H}_{3} \mathrm{BO}_{3}\left(0,050 \mathrm{~g} \mathrm{~L}^{-1}\right), \mathrm{CuCl}_{2} \cdot 2 \mathrm{H}_{2} \mathrm{O}\left(0,038 \mathrm{~g} \mathrm{~L}^{-}\right.$ $\left.{ }^{1}\right), \mathrm{CoCl}_{2} \cdot 6 \mathrm{H}_{2} \mathrm{O}\left(2,000 \mathrm{~g} \mathrm{~L}^{-1}\right), \mathrm{AlCl}_{3} \cdot 6 \mathrm{H}_{2} \mathrm{O}(0,090 \mathrm{~g}$ $\left.\mathrm{L}^{-1}\right),\left(\mathrm{NH}_{4}\right)_{6} \cdot \mathrm{Mo}_{7} \mathrm{O}_{24} \cdot 4 \mathrm{H}_{2} \mathrm{O}\left(0,050 \mathrm{~g} \mathrm{~L}^{-1}\right)$, EDTA $\left(1,000 \mathrm{~g} \mathrm{~L}^{-1}\right)$, resazurina $\left(0,200 \mathrm{~g} \mathrm{~L}^{-1}\right), \mathrm{HCl}(1,000$ $\left.m L^{-1}\right)$ e sua função foi disponibilizar nutrientes em concentrações traço para auxiliar no desempenho ótimo dos microrganismos, corrigir a salinidade e promover o tamponamento do meio (Florencio et al., 1993). A cada $1 \mathrm{~L}$ da solução de macronutriente utilizava-se $1 \mathrm{~mL}$ da solução de micronutrientes. Desta mistura foram adicionados $110 \mathrm{~mL}$ em cada reator.

Para corrigir as concentrações de ferro e de sulfato propostas no planejamento fatorial, foram preparadas soluções padrão destes minerais e transferidos volumes correspondentes para obter as concentrações desejadas em cada reator. A concentração de paracetamol foi de $1 \mathrm{~g} \mathrm{~L}^{-1}$ (Araújo et al., 2017). Após a mistura de todas as soluções, foi realizada a correção do $\mathrm{pH}$ para 7,2 $\pm 0,2 \mathrm{com}$ adição de ácido acético glacial (P.A.) ou hidróxido de sódio $40 \%$.

\section{Monitoramento}

A cada 48 horas coletou-se uma amostra do sobrenadante para a determinação da DQO e, a cada 24 horas, foi medido o metano produzido pelo deslocamento de líquido após lavagem de gás com solução de hidróxido de sódio 3\% e indicador de azul de bromotimol, como descrito por Aquino et al. (2007).

O tempo de incubação foi estimado de acordo com a velocidade de produção de metano. $\mathrm{O}$ período foi finalizado ao atingir a fase estacionária, isto é, quando se observou redução da velocidade de produção do metano acumulado. No início e no final do período de incubação foi analisada a concentração de paracetamol. A DQO foi analisada pelo método colorimétrico $5220 \mathrm{D}$ do Standard Methods for the examination of water and wastewater (APHA, 2012).

\section{Análise paracetamol}

A análise do paracetamol foi realizada por cromatografia líquida de alta eficiência (CLAE). As amostras foram previamente filtradas em filtro de PVDF 0,22 $\mu \mathrm{m}$ e transferidas para um recipiente de $2 \mathrm{~mL}$, do próprio cromatógrafo, da marca Shimadzu, modelo LC-20AT. A coluna utilizada foi uma C18 (Shim-pack CLC - ODS - M - 150mm x 4.6mm), detector de Arranjo de Diodos PDA 
(Photodiode Array detector). Injetou-se $100 \mu \mathrm{L}$, com fluxo de $1 \mathrm{~mL} \mathrm{~min}^{-1}$, a uma temperatura de $40^{\circ} \mathrm{C}$ de forno e a leitura foi feita no comprimento de onda de $248 \mathrm{~nm}$. As soluções eluentes utilizadas foram acetonitrila grau HPLC (solução A) e solução tampão fosfato $\mathrm{pH} 2,5\left(\mathrm{H}_{3} \mathrm{PO}_{4} \mathrm{e} \mathrm{Na} \mathrm{HPO}_{4}\right.$, $5 \mathrm{mM}$ ) (solução $\mathrm{B}$ ). A corrida durou seis minutos com uma mistura de 10/90 das soluções A e B.

\section{Resultados}

Degradação da matéria orgânica

Os cinco reatores receberam a mesma quantidade da solução de substrato e de paracetamol para que cada reator apresentasse concentração de DQO de $200 \mathrm{mg} \mathrm{O}_{2} \mathrm{~L}^{-1}$ e $30 \mathrm{mg}$ paracetamol L $\mathrm{L}^{-1}$, respectivamente. Em cada reator, diferentes quantidades das soluções de ferro e sulfato foram adicionadas, alterando o $\mathrm{pH}$. Desta forma, distintas quantidades de ácido acético PA foram adicionadas para ajustar o $\mathrm{pH}$ para 7,2 $\pm 0,2$. Após a mistura de todas as soluções, o valor da concentração de DQO inicial, em cada reator, foi diferente, pois o ácido acético é um ácido orgânico, podendo aumentar os valores da DQO.

A concentração da matéria orgânica, medida através da análise de DQO, após a correção do $\mathrm{pH}$ e ao longo do experimento em cada reator (Figura 1) variaram entre 300 e $800 \mathrm{mg} \mathrm{O}_{2} \mathrm{~L}^{-1}$.

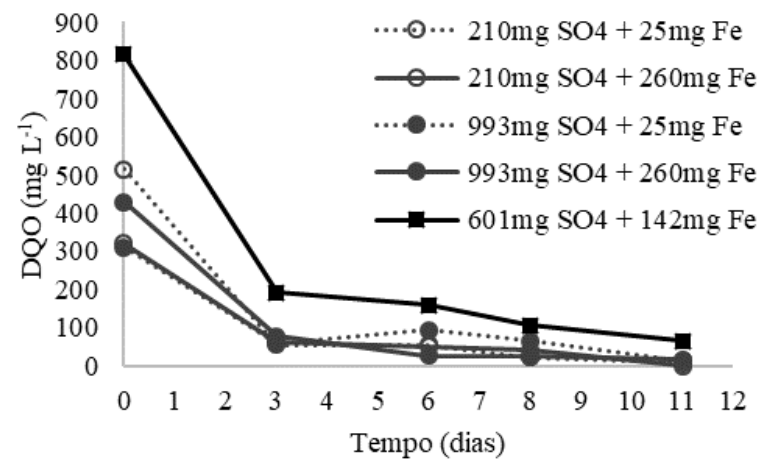

Figura 1. Degradação da DQO ao longo do tempo. Fonte: Guerra, Figueiroa \& Souza (2020).

No terceiro dia após a incubação dos reatores, ocorreu uma redução média de $83 \pm 5 \%$ da concentração de DQO, em todos os reatores, independente da concentração de ferro e de sulfato. Após 11 dias da incubação, a remoção média total de DQO atingiu percentagens de $89 \pm 6 \%$.

Cada reator recebeu diferentes dosagens de ferro e sulfato e, mesmo assim, as eficiências de remoção de matéria orgânica foram semelhantes entre eles. A Figura 2 mostra que, ao fixar a concentração de ferro, a remoção da DQO reduziu, em média, de $3 \pm 2 \%$, quando a concentração do sulfato aumentou de 210 para $993 \mathrm{mg} \mathrm{SO}_{4}^{-2} \mathrm{~L}^{-1}$. Ao fixar a concentração do sulfato, o aumento da concentração de ferro de 25 para $142 \mathrm{mg} \mathrm{Fe}^{2+} \mathrm{L}^{-1}$ promoveu uma redução média de $4 \pm 2 \%$ na remoção da matéria orgânica, enquanto o aumento de 142 para $210 \mathrm{mg} \mathrm{L}^{-1}$ promoveu um aumento de $6 \pm 1 \%$.

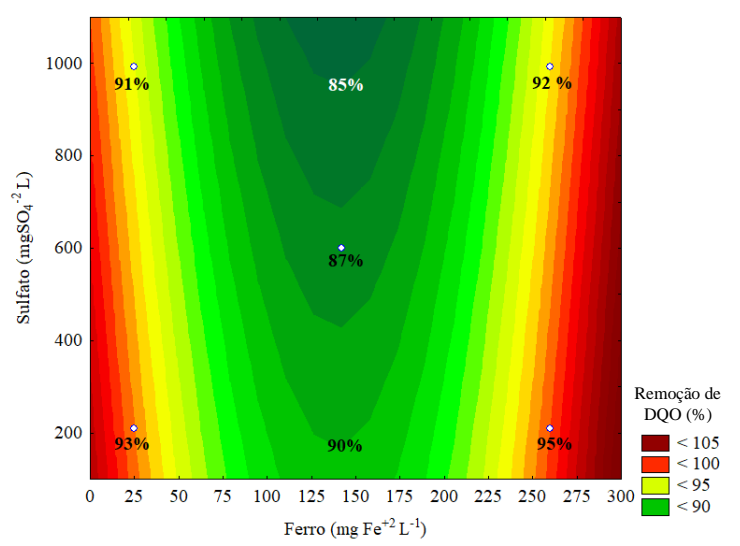

Figura 2. Superfície de resposta, em 2D, da interação do sulfato e do ferro na eficiência de remoção da DQO. Fonte: Guerra, Figueiroa \& Souza (2020).

A Figura 2 mostra que as variações das concentrações de sulfato e ferro testadas não comprometeram a remoção da matéria orgânica, pois em todas as situações testadas, o percentual foi superior a $80 \%$. Todavia, houve uma correlação quadrática entre a concentração de ferro e a eficiência de remoção de matéria orgânica. Todas as rotas de degradação anaeróbia de matéria orgânica são capazes de reduzir o valor de DQO, a diferença está no produto final, isto é, na composição do biogás e na velocidade da atividade microbiana.

Apesar dos reatores terem percentuais de degradação total de DQO semelhantes, a taxa (velocidade) de degradação foi mais elevada nos primeiros cinco dias, em todos eles e diferente entre si $(\rho=0,01401$, Teste $t=4,17,4$ graus de liberdade e $\alpha=0,05$ ). Após este período, as taxas decresceram e se igualaram, como pode ser observado na Figura $3 \mathrm{AB}$.

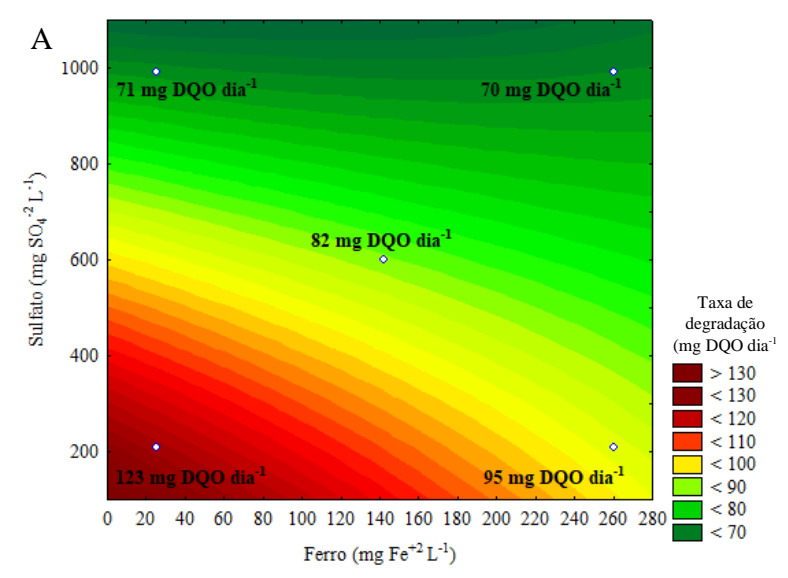




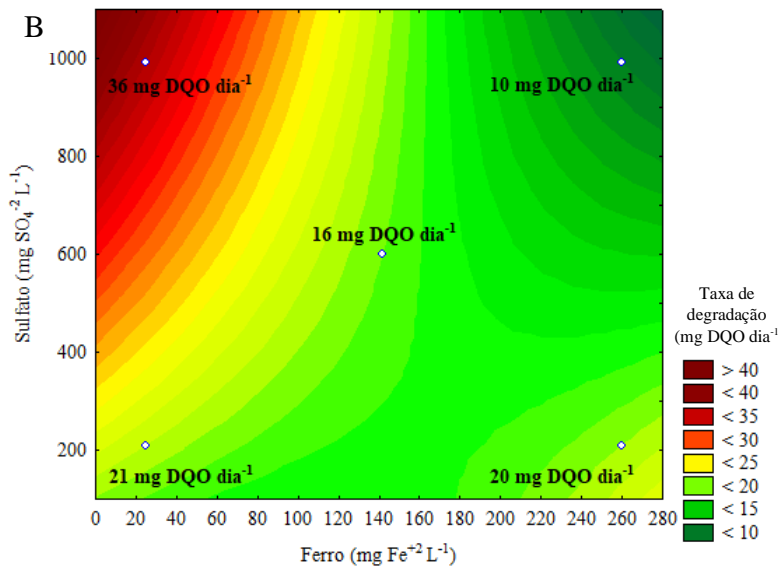

Figura 3. Superfície de resposta das taxas de degradação da DQO, A. no período de cinco dias; B. no período de 10 dias. Fonte: Guerra, Figueiroa \& Souza (2020).

A Figura 3A mostra que o aumento do sulfato provocou uma redução da taxa de degradação de $52 \%$ e $25 \%$, quando as concentrações do ferro foram de 25 e $260 \mathrm{mg} \mathrm{Fe}^{2+}$ $\mathrm{L}^{-1}$, respectivamente. $\mathrm{O}$ aumento da concentração do ferro só interferiu com uma redução de $28 \%$, quando a concentração do sulfato foi inferior a 610 $\mathrm{mg} \mathrm{SO}_{4}^{-2} \mathrm{~L}^{-1}$. O ferro minimizou o efeito negativo provocado pelo sulfato. A maior taxa de degradação foi observada no $5^{\circ}$ dia de incubação, com redução de $123 \mathrm{mg} \mathrm{DQO}$ dia $^{-1}$, que ocorreu nos reatores com $210 \mathrm{mg} \mathrm{SO}_{4}^{-2} \mathrm{~L}^{-1}$ e $25 \mathrm{mg} \mathrm{Fe}^{2+} \mathrm{L}^{-}$ ${ }^{1}$ constituindo as menores concentrações de cada elemento.

Nestes primeiros cinco dias, nos reatores com as concentrações mais elevadas de sulfato e de ferro, $993 \mathrm{mg} \mathrm{SO}{ }^{-2} \mathrm{~L}^{-1}$ e $260 \mathrm{mg} \mathrm{Fe}^{2+} \mathrm{L}^{-1}$, respectivamente, a taxa foi de $70 \pm 1 \mathrm{mg}$ DQO dia $1,53 \pm 1 \%$, inferior ao reator com as menores concentrações de ferro e sulfato.

No $10^{\circ}$ dia de incubação, as taxas de degradação reduziram para valores inferiores a 40 mg DQO dia $^{-1}$. Esta redução estava vinculada à redução da disponibilidade de matéria orgânica e à redução da relação DQO:sulfato. Observa-se, na Figura 3B, que a taxa mais elevada não ocorreu nas mesmas condições que no $5^{\circ}$ dia.

\section{Produção de metano}

Ao avaliar a produção de metano acumulada, isto é, a quantidade total de metano produzida durante todo o período de incubação, em aproximadamente 11 dias, foi possível verificar que a maior produção de metano ocorreu quando as concentrações de ferro foram as mais elevadas, como mostra a Figura 4.

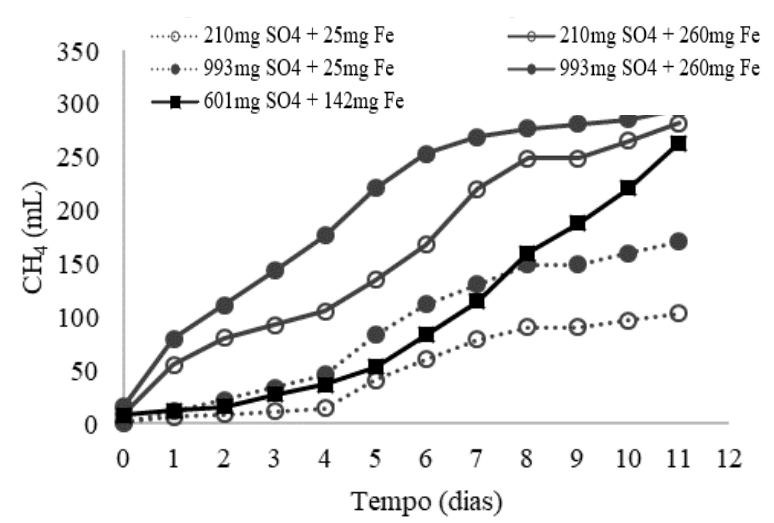

Figura 4. Eficiência de produção acumulada de metano. Fonte: Guerra, Figueiroa \& Souza (2020).

A produção de metano confirma a atividade das arqueas metanogênica (AM). Comparando a produção de metano com a degradação da matéria orgânica, pode-se verificar que a redução da DQO, até o $5^{\circ}$ dia, foi superior a $80 \%$, em todos os reatores, mas a produção do metano, neste mesmo período, foi maior nos reatores com as concentrações mais elevadas de ferro, independente da concentração de sulfato. Até o $5^{\circ}$ dia, os reatores com $260 \mathrm{mg} \mathrm{Fe}{ }^{2+} \mathrm{L}^{-1}$ tinham produzido cerca de $47 \pm 4 \%$ do metano. Nos reatores com as menores concentrações de ferro e sulfato, a produção foi de apenas $8 \%$ neste mesmo período. Os reatores com as concentrações de sulfato mais elevadas tinham as relações de DQO:sulfato mais baixas. No entanto, no reator com $260 \mathrm{mg} \mathrm{Fe}^{2+} \mathrm{L}^{-1}$, a produção de metano foi de $50 \%$ e, na presença de $25 \mathrm{mg} \mathrm{Fe}^{2+} \mathrm{L}^{-1}$, a produção de metano foi de apenas 29\%. A Figura 5 mostra a interação das concentrações de ferro e sulfato, quando pode-se observar que, nos reatores com a concentração de $260 \mathrm{mg} \mathrm{Fe} \mathrm{Fe}^{2+} \mathrm{L}^{-1}$, a produção de metano foi mais elevada.

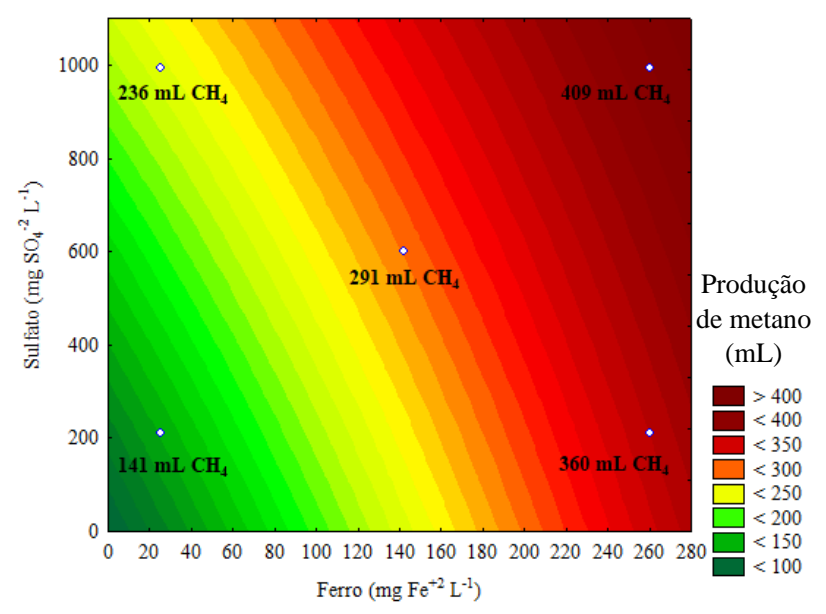

Figura 5. Interferência do sulfato e do ferro na produção acumulada de metano. Fonte: Guerra, Figueiroa \& Souza (2020). 


\section{Eficiência de remoção do paracetamol}

Houve a redução da concentração do composto paracetamol superior a $60 \%$ em todos os reatores, com exceção do reator com $25 \mathrm{mg} \mathrm{Fe}^{2+} \mathrm{L}^{-}$ ${ }^{1}$ e $993 \mathrm{mg} \mathrm{SO}_{4}^{-2} \mathrm{~L}^{-1}$, que foi de 35\%, como mostra a Figura 6.

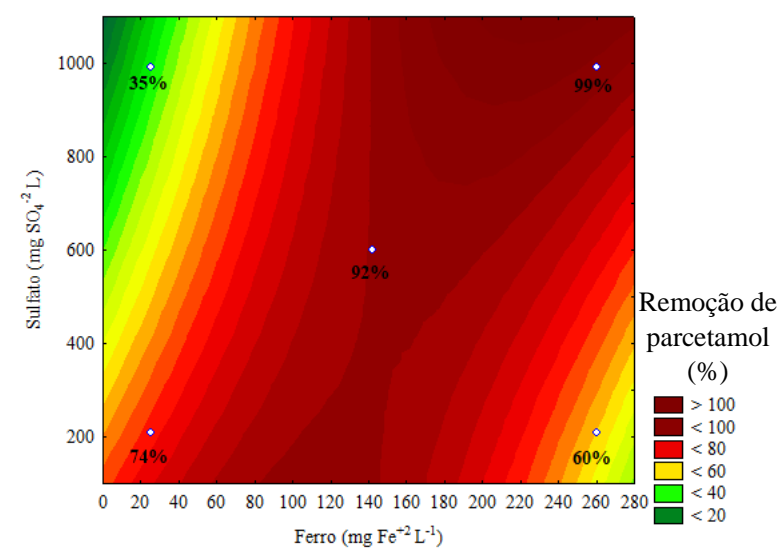

Figura 6. Superfície de resposta da interação do sulfato e do ferro na remoção de paracetamol. Fonte: Guerra, Figueiroa \& Souza (2020).

A Figura 6 mostra que o maior percentual de degradação do paracetamol foi de $99 \%$ quando as concentrações de ferro e sulfato eram as máximas, $260 \mathrm{mg} \mathrm{Fe}^{2+} \mathrm{L}^{-1}$ e $993 \mathrm{mg} \mathrm{SO}_{4}{ }^{-2} \mathrm{~L}^{-1}$. Resultados semelhantes (92\%) foram observados quando as concentrações foram de $142 \mathrm{mg} \mathrm{Fe}^{2+} \mathrm{L}^{-1}$ e $601 \mathrm{mg} \mathrm{SO}{ }_{4}^{-2} \mathrm{~L}^{-1}$. Em ambas as situações, a relação de sulfato:ferro foi semelhante, $3,8: 1 \mathrm{e}$ 4,2:1, respectivamente. Quando a concentração de ferro foi de $25 \mathrm{mg} \mathrm{Fe}^{2+} \mathrm{L}^{-1}$, a relação de sulfato:ferro foi de 8:1 e 40:1, quando as concentrações de sulfato foram de 210 e $993 \mathrm{mg}$ $\mathrm{SO}_{4}{ }^{-2} \mathrm{~L}^{-1}$, respectivamente. Nestas condições, os percentuais de degradação do paracetamol reduziram para $74 \%$ e $35 \%$, sugerindo que a quantidade de ferro foi insuficiente para a quantidade de sulfato. Ao elevar a concentração de ferro para $260 \mathrm{mg} \mathrm{Fe}^{2+} \mathrm{L}^{-1}$ e manter a concentração do sulfato no valor mínimo, em $210 \mathrm{mg} \mathrm{SO}_{4}{ }^{-2} \mathrm{~L}^{-1}$, houve uma redução da eficiência para aproximadamente $60 \%$.

\section{Discussão}

O esgoto sintético utilizado nos reatores mostrou características semelhantes aos esgotos domésticos e a concentração da matéria orgânica variou entre 300 e $800 \mathrm{mgO}_{2} \mathrm{~L}^{-1}$. Esta faixa de valores é condizente com concentrações de esgoto doméstico bruto encontrado em diversos estados brasileiros: $257 \mathrm{mg} \mathrm{O}_{2} \mathrm{~L}^{-1}$ em Porto Alegre (Cybis, Santos \& Gehling, 2004); em Campos Novos (Santa Catarina), os valores de DQO variaram entre 400 e $600 \mathrm{mg} \mathrm{O}_{2} \mathrm{~L}^{-1}$ (Lourenço et al., 2018); em
Araras-SP, a variação anual ficou na faixa de 104 a $2044 \mathrm{mg} \mathrm{O}_{2} \mathrm{~L}^{-1}$ e uma média de $479 \mathrm{mg} \mathrm{O}_{2} \mathrm{~L}^{-1}$ (Souza et al., 2015).

Para reatores anaeróbios, utilizados em unidades de tratamento de esgoto industriais ou domésticos, em escala real de ótimo desempenho, a literatura relata eficiências superiores a $80 \%$ para a remoção da matéria orgânica (Chernicharo et al., 2015). Desta forma, o desempenho dos reatores utilizados neste estudo foi satisfatório e condizente com os sistemas de alto desempenho, visto que aproximadamente $89 \%$ da concentração de matéria orgânica foi removida ao final do período de incubação.

No reator cujas concentrações de sulfato e ferro foram elevadas, $993 \mathrm{mg} \mathrm{SO}_{4}^{-2} \mathrm{~L}^{-1}$ e $260 \mathrm{mg}$ $\mathrm{Fe}^{2+} \mathrm{L}^{-1}$, respectivamente, houve redução na taxa de degradação da matéria orgânica, principalmente nos cinco primeiros dias de incubação. Neste reator, a redução da taxa pode ter ocorrido devido a uma maior competição entre as bactérias redutoras de sulfato (BRS) e as metanogênicas, corroborando o estudo de Muyzer \& Stams (2008), pois a relação DQO:sulfato no reator com a maior velocidade foi de 2,4 e no reator com as maiores concentrações de ferro e sulfato foi de 0,43. Callado, Damianovic \& Foresti (2017) afirmam que a relação DQO:sulfato não é o fator responsável para a inibição da atividade metanogênica e, sim, a concentração de sulfetos e sódio. Logo, baixos valores da relação DQO:sulfato aumentam a atividade das BRS com a produção e liberação de sulfetos, e este pode ser o fator de inibição da atividade metanogênica.

A partir do $10^{\circ}$ dia de incubação, a taxa de degradação da matéria orgânica foi melhor em concentrações de sulfato mais elevadas $(993 \mathrm{mg}$ $\left.\mathrm{SO}_{4}^{-2} \mathrm{~L}^{-1}\right)$, baixa concentração de ferro $\left(25 \mathrm{mg} \mathrm{Fe} \mathrm{ge}^{2+}\right.$ $\left.\mathrm{L}^{-1}\right)$ e baixa relação DQO:sulfato $(0,09)$, que sugerem um ambiente propício para a atividade das BRS.

Neste experimento, pode-se observar que o grupo de microrganismos metanogênicos foram os responsáveis pela redução da DQO, pois os valores de ferro e sulfato eram inferiores ao necessário para ocorrer a rota de redução do ferro e do sulfato e a relação DQO:sulfato era a mais alta dentre os reatores, 2,45. Segundo Muyzer \& Stams (2008), as bactérias redutoras de sulfato (BRS) competem com as acetogênicas produtoras de hidrogênio (APH) e as arqueas metanogênicas (AM) pelo substrato hidrogênio e acetato, apenas quando a concentração de sulfato é elevada em águas residuárias. Eles afirmam que a maior afinidade ao substrato pelas BRS as torna mais competitiva principalmente quando a relação DQO:sulfato diminui. 
A eficiência de remoção de DQO foi igual em todos os reatores, superior a $80 \%$ independente das concentrações de ferro e sulfato. No entanto, a velocidade de degradação foi maior nos primeiros cinco dias e nas menores concentrações de sulfato e ferro. Neste período, a relação de DQO:sulfato foi de 2,4 , inibindo a ação das BRS. No período de cinco a 10 dias, a relação DQO:sulfato reduziu devido a degradação da matéria orgânica, tornando o ambiente mais propício para o desenvolvimento das BRS e redução da atividade das AM.

Em relação à produção de metano, Soares, Feiden \& Tavares (2017) afirmam que o ferro é um dos nutrientes mais importantes na estimulação da digestão anaeróbia. Silva, Yabuki \& Garcia (2019) operaram um biodigestor anaeróbio com melaço como substrato e diferentes concentrações de ferro $\left(0,15\right.$ a $\left.2,16 \mathrm{mg} \mathrm{L}^{-1}\right)$, em conjunto com manganês $\left(0,026\right.$ a $\left.0,392 \mathrm{mg} \mathrm{L}^{-1}\right)$ e cobre $\left(0,037\right.$ e $0,45 \mathrm{mg} \mathrm{L}^{-}$ ${ }^{1}$ ), e não observaram diferenças significativas na eficiência de produção de metano. Martins (2018) verificou que o ferro era utilizado em conjunto com outros elementos em diversos processos bioquímicos dos microrganismos anaeróbios e o aumento da sua concentração pode resultar em aumento ou redução da eficiência de produção de metano, e está diretamente relacionada com a concentração simultânea de outros elementos traço, como níquel, cobalto e cobre. Martins (2018) investigou concentrações de ferro entre 5 e $50 \mathrm{mg}$ $\mathrm{L}^{-1}$ e observou efeitos positivos, quando associado apenas com cobalto, e efeito negativo, quando associado com cobalto e níquel, simultaneamente. No presente estudo, o ferro em conjunto com o sulfato, para baixas relações de DQO:sulfato, favoreceram a produção do metano. Ao final de 11 dias, os reatores com $260 \mathrm{mg} \mathrm{Fe}^{2+} \mathrm{L}^{-1}$ produziram $100 \%$ do metano previsto e os reatores com $25 \mathrm{mg}$ $\mathrm{Fe}^{2+} \mathrm{L}^{-1}$ produziram $27 \%$ e $68 \%$ quando as concentrações de sulfato foram de 210 e $993 \mathrm{mg}$ $\mathrm{SO}_{4}{ }^{-2} \mathrm{~L}^{-1}$, respectivamente. Desta forma, o ferro favoreceu a atividade das AM e, em conjunto com o sulfato, aumentou a produção do metano nos reatores anaeróbios.

Desta forma, a degradação do paracetamol necessita dos dois elementos, mas, respeitando a proporção de 4:1 (sulfato:ferro) e admitindo que a falta de ferro tem impacto negativo mais intenso que a falta do sulfato.

\section{Conclusão}

Concluímos que houve atividade das arqueas metanogênicas (AM) e das bactérias redutoras de sulfato (BRS) na degradação da matéria orgânica e do paracetamol. O paracetamol foi degradado de forma satisfatória (acima de 60\%) nos reatores anaeróbios sem alterar o desempenho dos microrganismos, pois a concentração inicial foi a mesma em todas as situações. Apenas o reator com $25 \mathrm{mg} \mathrm{Fe}^{2+} \mathrm{L}^{-1}$ e $993 \mathrm{mg} \mathrm{SO}_{4}^{-2} \mathrm{~L}^{-1}$ apresentou eficiência inferior à de $40 \%$. As concentrações mais elevadas de ferro e sulfato (260 e $993 \mathrm{mg} \mathrm{L}^{-1}$, respectivamente) promoveram as maiores eficiências de produção de metano e de degradação de paracetamol. A interação entre o ferro e o sulfato foi importante e relevante para o desenvolvimento satisfatório dos microrganismos anaeróbios na degradação do paracetamol. Para isso, deve-se promover baixa relação DQO:sulfato e uma proporção de sulfato:ferro de 4:1.

\section{Agradecimentos}

Os autores agradecem ao Programa de Apoio aos Núcleos de Excelência (Pronex) pelo auxílio financeiro, e ao Centro Universitário Tabosa de Almeida (ASCES-UNITA) por disponibilizar os laboratórios e equipamentos necessários para a realização deste estudo.

\section{Referências}

ABRELPE. 2017. Associação Brasileira de Empresas de Limpeza Pública e Resíduos Especiais. Panorama dos resíduos sólidos no Brasil.

Américo, J. H. P.; Minillo, A.; Carvalho, S. L. 2012. Detecção do analgésico paracetamol no Córrego da Onça, Três Lagoas - MS. Fórum Ambiental da Alta Paulista, 8, 12, 38-47, DOI: $10.17271 / 198008278122012353$

APHA. 2012. American Public Health Association. Standard Methods for The Examination of Water and Wastewater. 22 ed. Washington: APHA, 2012. 1504p.

Aquino, S. F.; Chernicharo, C. A. L.; Foresti, E.; Florêncio, M. L. S.; Monteggia, L. O. 2007 Metodologias para determinação da Atividade Metanogênica Específica (AME) em Lodos Anaeróbios. Engenharia Sanitária e Ambiental, 12, 2, 192-201. DOI: 10.1590/s1413-41522007000200010

Araújo, N. M. C.; Silva, D. A.; Silva Júnior, M. J.; Barros, K. K.; Souza, L. F. C. 2017. Chapter 8.1 Water bodies modification caused by effluents with paracetamol. I. (Editors): Environmental Biotechnology and Engineering: ISEBE Advances 2016, Ed. Cinvestav, Mexico City, Mexico, pp. 789797.

Bachur, T. P. R.; Freitas, J. A. B.; Fonteles, M. M. F.; Lima, M. E. S. Bachur, T. P. R.; Carvalho, T. M. J. P. 2017. Medicamentos isentos de prescrição: perfil de consumo e os riscos tóxicos do paracetamol. Revinter, 10, 03, 
$134-154$

DOI:

10.22280/revintervol10ed3.337.

Bila, D. M.; Dezotti, M. 2003. Antibióticos no meio ambiente. Química Nova, 26, 4, 523530.

DOI: 10.1590/S010040422003000400015

Borges, R. S.; Jesus, A. C. S. P. S.; Cardoso, L. F.; Neri, C. L.; Morais, R. B.; Barros, V. A.; Silva, A. B. F. 2018. Avanços Químicos no planejamento e desenvolvimento de derivados do paracetamol. Química Nova, 41, 10, 1167-1177. DOI: 10.1590/s141341522016140811.

Brasil 2010. Decreto Lei $\mathrm{n}^{\circ} 12.305$, de 2 de agosto de 2010. Institui a Política Nacional de Resíduos Sólidos, altera a Lei ${ }^{\circ}$ 9.605, de 12 de fevereiro de 1998 e dá outras providências.

Brasil 2013. Ministério da Saúde Consultoria Jurídica/Advocacia Geral da União. Nota Técnica $\mathrm{N}^{\circ} 346 / 2013$. Brasília.

Brasil 2016. Ministério da Saúde. Caderno de anotações relatos de experiências da Semana Saúde na Escola. Versão preliminar, Brasília. $34 \mathrm{p}$.

Callado, N. H.; Damianovic, M. H. Z.; Foresti, E. 2017. Influência da razão $\mathrm{DQO} /\left[\mathrm{SO}_{4}{ }^{2-}\right]$ e da concentração de $\mathrm{Na}^{+}$na remoção de matéria orgânica e sulfato em reator UASB. Engenharia Sanitária Ambiental, 22, 2, 381390. DOI: 10.1590/s1413-41522016140811.

Chen, Y.; Cheng, J. J.; Creamer, K. S. 2008. Inhibition of anaerobic digestion process: A review. Bioresource Technology, 10, 99, 4044-4064.

DOI: 10.1016/j.biortech.2007.01.057.

Chernicharo, C. A. L. 2007. Princípios do tratamento biológico de águas residuária: Reatores anaeróbios. $2^{\circ}$ ed. Belo Horizonte: Brasil. 379p.

Chernicharo, C. A. L.; Van Lier, J. B.; Noyola, A.; Bressani Ribeiro, T. 2015. Anaerobic sewage treatment: state of the art, constraints and challenges. Reviews in Environmental Science and Bio/Technology, 4, 14, 649-679. DOI: $10.1007 / \mathrm{s} 11157-015-9377-3$.

Cybis, L. F. A.; Santos, A. V.; Gehling, G. R. 2004. Eficiência do reator sequencial em batelada (RSB) na remoção de nitrogênio no tratamento de esgoto doméstico com DQO baixa. Engenharia Sanitária Ambiental, 9, 3, 260-264.

DOI:

10.1590/S14131522004000300012

Florencio, L.; Jenicek, P.; Field, J., Lettinga, G. 1993. Effect of cobalt on the anaerobic degradation of methanol. Journal of Bioscience and Bioengineering, 75, 5, 368374. DOI: 10.1016/0922-338X(93)90136-V.
Ghiselli, G.; Jardim, W. F. 2007. Interferentes endócrinos no ambiente. Química Nova, 30, 3 , 695-706. DOI: 10.1590/S010040422007000300032.

Goodman e Gilman 2003. As bases farmacológicas da terapêutica. Rio de Janeiro; McGraw Hill, ed. $10.1433 p$.

Guerra, E. D.; Matos, J. S.; Andrade, A. M. C.; Cordeiro, R. P.; Souza, L. F. C. 2017. The effects of environmental education at the medicine discharge in Caruaru City-PE, Brazil. In: Candal, R. et al. [eds]: Environmental Biotechnology and Engineering: ISEBE Advances 2016, Cinvestav, Mexico City, Mexico, pp. 870879.

Lourenço, L. S.; Rodrigues, E. B.; Moreira, M. A.; Skoronski, E. 2018. Remoção de matéria orgânica e nutrientes de esgoto doméstico por wetland horizontal de fluxo subsuperficial na estação de tratamento de Aparecida - Campos Novos, SC. Revista Brasileira de Agropecuária Sustentável, 8, 1, 85-94. DOI: 10.21206/rbas.v8i1.483

Madigan, M. T.; Martinko, J. M.; Bender, K. S.; Buckley, D. H.; Stahl, D. A. 2010. Microbiologia de Brock. $12^{\circ}$ ed. Porto Alegre: Artmed. 1128p.

Martins, A. S. 2018. Digestão anaeróbia de resíduos alimentares: efeito da carga orgânica e da adição de elementos traços sobre a produção de metano e a diversidade microbiana. Tese Doutorado, Universidade Federal de Minas Gerais, Belo Horizonte, Minas Gerais, Brasil. 169p.

Muyzer, G.; Stams, A. J. M. 2008. The ecology and biotechnology of sulphate-reducing bacteria. Nature Reviews Microbiology, v. 6, n. 6, p. 441-454. DOI: 10.1038/nrmicro1892.

Silva, C. M. R.; Yabuki, L. N. M.; Garcia, M. L. 2019. Monitoramento das concentrações totais de cobre, ferro e manganês na digestão anaeróbia de melaço. Holos Environment, 19, 2, 175-189. DOI: 10.14295/holos.v19i2.12324.

Silva, M. R. L. 2012. Caracterização da comunidade microbiana de biofilme anaeróbio em presença de Bifenilas Policloradas. Dissertação mestrado, Universidade de São Paulo, São Carlos, São Paulo, Brasil. 126p.

Soares, C. M.T.; Feiden, A.; Tavares, S. G. 2017. Fatores que influenciam o processo de digestão anaeróbia na produção de biogás. Nativa, SINOP, 5, 522-528. DOI: 10.5935/23187670.v05nespa10. 
Souza, C. F.; Bastos, R. G.; Gomes, M. P. M.; Pulschen, A. A. 2015. Eficiência de estação de tratamento de esgoto doméstico visando reuso agrícola. Ambiente e Água - An Interdiciplinary Journal of Applied Science, 10, 3, 587-597. DOI: 10.4136/ambiagua.1549.

Szarblewski, M. S.; Schneider, R. C. S.; Machado, E. L. 2012. Métodos para a remoção de sulfeto de hidrogênio de efluentes gasosos aplicáveis a reatores anaeróbios. Revista
Jovens Pesquisadores, 1, 62-74. DOI: 10.17058/rjp.v0i1.2865

Torres, P. 1992. Desempenho de um Reator Anaeróbio de Manta de Lodo (UASB) de Bancada no Tratamento de Substrato Sintético Simulando Esgoto Sanitário. Dissertação de Mestrado, Escola de Engenharia de São Carlos, Universidade de São Paulo, São Carlos, São Paulo, Brasil. 185 p. 